\title{
Taking Biology Seriously: What Biology Can and Cannot Tell Us About Moral and Public Policy Issues
}

Autora: Inmaculada De Melo-Martín

Rowman \& Littlefield, 2005, 161 páginas

\author{
El papel del determinismo biológico en los asuntos \\ político-morales y el alcance de la deliberación bioética*
}

Por Noemí Sanz Merino

\begin{abstract}
Desde las expectativas generadas por el comienzo del Proyecto Genoma Humano en 1990, pasando por el nacimiento de la primera copia de un mamífero adulto con Dolly en 1996, hasta la aprobación en España del Decreto de Ley sobre investigación biomédica el 15 de septiembre de 2006 -que, como la actual ley británica, regulará la investigación con células madre embrionarias y quizá a generar éstas con técnicas de clonación- nuestra capacidad biotecnológica nos ha concedido en apenas una década un futuro inmediato de posibilidades revolucionarias aparentemente infinitas. No es de extrañar que esta situación despierte las más radicales fobias y filias al mismo tiempo, pues si algo es seguro es que los distintos usos que hagamos de las nuevas tecnologías y conocimientos científicos de los que ahora disponemos al respecto repercutirán de manera directa e inmediata no sólo en todos los niveles y esferas sociales sino también en nuestra concepción de la naturaleza humana.
\end{abstract}

La polémica, ya suscitada cuando estas posibilidades estaban más cercanas a la ciencia ficción que a la realidad, no parece, en cambio, haber variado cualitativamente sus términos. Se trata de un debate en el que, aparentemente, lo único tomado como incuestionable es la facticidad y progreso inexorable del conocimiento genético y su aplicabilidad, y en el que se tiende a identificar la defensa o no del uso de estas biotecnologías con el apoyo o no a la inclusión del conocimiento científico en los asuntos políticos y morales. Es en este contexto donde el último libro de la filósofa Inmaculada de Melo-Martín se sitúa, al desvelarnos que tanto los que abrazan estos nuevos saberes y habilidades, como los que los temen, desarrollan sus argumentos en maneras incorrectas.

\footnotetext{
* Este trabajo no habría sido posible sin el apoyo y financiación de la Fundación para el Fomento en Asturias de la Investigación Científica Aplicada y la Tecnología (FICYT), así como del Ministerio de Educación y Ciencia a través del Proyecto de Investigación básica "Apropiación social de la ciencia" (HUM200506760/FISO).
} 
Taking Biology Seriously es el resultado de evaluar algunos de los malentendidos presentes en muchos de los discursos sobre biología y sus consecuencias para la moralidad y las políticas públicas. Con él, la autora lleva a cabo la necesaria tarea de poner el debate biotecnológico en sus justos términos: por un lado, atendiendo al conocimiento biotecnológico con el que podemos contar actualmente -destacando así la necesidad de conocer los aspectos científico-tecnológicos implicados, lo que demuestra en los capítulos dedicados a introducirnos en los aspectos técnicos relacionados con los distintos ejemplos presentados a debate- $y$, por otro lado, aunque vinculado con lo anterior, denunciando y contra-argumentando la tendencia a considerar la ciencia y tecnologías genéticas como fuerzas poderosas -ya sean temibles o beneficiosas- "cuyas consecuencias pueden ser evaluadas independientemente del contexto social, político y ético en el cual viven los seres humanos" (p. 2).

Tomar la biología seriamente es, entonces, responder rigurosamente a las cuestiones acerca de qué nos pueden decir la ciencia y la tecnología sobre la biología humana y, en segundo lugar, qué no nos pueden decir con respecto a las cuestiones morales y políticas que se suscitan. Para ello, Inmaculada de Melo-Martín escoge someter a análisis tres polémicas concretas dentro del habitual marco de debate bioético en torno a las nuevas posibilidades biotecnológicas: a) si los genes determinan el comportamiento humano, entonces la responsabilidad social se vería disminuida; b) la moralidad o no de la clonación humana reproductiva; y c) la existencia o no de obligación moral acerca de conocer nuestra dotación genética y de actuar en vistas al bien común con respecto a la misma.

Cabría señalar aquí que, si bien es cierto que la clonación reproductiva sigue siendo una fuente de intranquilidad social -por el hecho mismo de que poseamos tal posibilidad técnica- a pesar de que hay un rechazo generalizado de la misma, se echan de menos otras cuestiones de especial urgencia actual y que no se analizan en el presente libro, siendo el caso, por ejemplo, de la clonación terapéutica. Aún así, el objetivo de este trabajo se logra con éxito a través de tres ejemplos que no sólo no son excluyentes de otros iguales o más relevantes hoy en día, sino que, en todo caso, son altamente significativos por recibir y despertar especial atención y polémica tanto en la discusión académica como en los medios de comunicación y entre el público en general, así como por ser controversias que entrañan desde deberes morales individuales hasta responsabilidades societarias. En concreto, y tal y como nos explica su autora, son ejemplos representativos del hecho recurrente de que los distintos argumentos expuestos, tanto a favor como en contra, están basados sobre los errores epistemológicos, científicos y morales que de Melo-Martín quiere denunciar aquí por contribuir a la presuposición de un reduccionismo y determinismo biológico que, así planteados, no sólo son falsos sino peligrosos.

La primera equivocación puesta de relieve es la de asumir que el conocimiento sobre un rasgo o comportamiento biológico particular nos aporta también conocimiento sobre los valores de tal rasgo. Este error epistemológico fundamental respalda, por ejemplo, el reduccionismo de creer que sólo el saber científico es relevante cuando se trata de valorar ciertos rasgos humanos. La segunda concierne 
a una mala interpretación acerca del propio contenido de la ciencia. A pesar de que la Biología reconoce la importancia de otros factores, además de los genéticos -ya sean medioambientales, sociales u otros elementos biológicos- para entender el funcionamiento de nuestros genes, éstos son habitualmente pensados como más necesarios y cercanos a suficientes que los otros. Por ejemplo, mientras la ciencia nos dice que la expresión de algunos genes está afectada por el ambiente celular, en cambio, está muy lejos de poder dar cuenta de cómo lo hace. Por lo tanto, según la autora, cuáles de todos estos factores son meramente contextuales y cuáles más directamente determinantes es más una elección pragmática de los expertos que una imposición del mundo. De la misma manera, si es el caso que estas conclusiones no están impuestas por el mundo, entonces están abiertas a evaluación.

A este segundo error se le suman además los malentendidos acerca de las tecnologías involucradas. Por ejemplo, si se parte de que sólo los genes son relevantes cuando se trata de predecir nuestro estado físico futuro, esto también implica asumir que las tecnologías usadas para identificar nuestro material genético nos proporcionan información suficiente y necesaria sobre nuestra salud futura o el desarrollo de determinados rasgos biológicos y comportamentales.

Por último y relacionado con lo anterior, se suele asumir que nuestra habilidad técnica para obtener información sobre nuestra herencia genética y la de nuestra descendencia es suficiente para justificar obligaciones morales. Inmaculada de MeloMartín muestra a este respecto cómo los debates éticos y políticos acerca de estas cuestiones parten de un planteamiento inadecuado de los asuntos morales mismos en conflicto: porque, incluso siendo el caso o no de cierto determinismo biológico, encierran una presuposición acerca de la irrelevancia del contexto social donde las diferentes demandas morales aparecen.

El reduccionismo compartido por estas asunciones epistemológicas, científicotecnológicas y morales no sólo implicaría, por lo tanto, una simplificación de la naturaleza humana en general sino de nuestra propia naturaleza biológica en particular. Veámoslo más detalladamente atendiendo brevemente a los propios ejemplos ofrecidos en este libro.

Para ejemplificar y evaluar el primero de los dilemas morales escogidos, de MeloMartín toma cuatro de las cuestiones tradicionalmente objeto del debate herencia versus ambiente: la inteligencia, las conductas agresiva y adictiva, y las diferencias sexuales en estrategias reproductivas. Según la autora, aún hoy las discusiones en torno a ellas se plantean acerca de su determinismo biológico, asumiéndose, por tanto, que si fuera el caso, entonces la responsabilidad social de los individuos genéticamente determinados no existiría. En cambio, como de Melo-Martín muestra en el segundo capítulo, "Biological Explanations and Social Responsability", tal controversia está mal concebida. Por un lado, los que plantean el debate en esos términos "presuponen erróneamente que los rasgos y comportamientos humanos son intrínsecamente buenos o malos, apropiados e inapropiados, convenientes o inconvenientes" ( $p$. 18). Por otro lado, y aun siendo verdad que la ciencia pueda predecir certeramente qué rasgos fenotípicos desarrollaremos en el futuro, el 
conocimiento biológico no puede evaluarlos independientemente de los contextos ambientales, sociales y políticos, pues muchos de esos rasgos biológicos y comportamentales difieren en valor respecto del contexto social en el que se expresan. Así, la autora explica por qué la biología sólo puede ofrecernos explicaciones problemáticas acerca de la inteligencia humana, la diferencia sexual, la agresividad y el comportamiento adictivo de los seres humanos: porque en tales casos se está ocupando de características que deben ser valoradas en contextos histórico-sociales concretos. Por lo tanto, y de nuevo sea o no el caso de que los rasgos humanos están determinados biológicamente, la conclusión acerca de la desaparición de responsabilidad social no se sigue. Pues si los contextos sociales cambian históricamente, los criterios desde los que se juzgan y atribuyen responsabilidades también lo hacen.

Tras un capítulo introductorio a la historia y técnica de la clonación, en el cuarto capítulo, "Cloning -or not- Human Beings", y en el quinto, "Putting Human Cloning Where it Belongs", la autora evalúa respectivamente qué puede y qué no puede el conocimiento biológico aportar a los habituales argumentos en contra y a favor de la clonación reproductiva de seres humanos. Su intención aquí es dar una atención cuidadosa al conocimiento científico disponible y así poder rechazar, al menos, aquellos reclamos que se basen en una mala interpretación de la ciencia, pues "si vinculamos nuestras demandas morales con conocimiento biológico relevante, y si podemos mostrar que tal conocimiento no puede justificar tales reclamos, entonces debemos cambiar tales creencias morales o vincularlas con otros conocimientos biológicos actuales. Esto es algo que la biología puede decirnos” (p. 9). En este contexto, e incluso tras aceptar el hecho de que los argumentos que defienden la clonación no son cuestionables en términos científicos, los argumentos a favor "yerran porque se debilitan al tomar en cuenta el contexto social en el cual la clonación reproductiva tendría un lugar" (p. 63). Inmaculada de Melo-Martín toma en cuenta el mundo real donde las demandas a favor de la clonación son solicitadas y argumenta que, en todo caso, hay buenas razones para dudar de la moralidad de proceder con esta tecnología. Diciéndolo en otros términos, la autora nos muestra cómo el no tomar en consideración las circunstancias sociales a la hora de decidir acerca de su aplicación es realmente el falso dilema y no al contrario. La biología, entonces, no puede decirnos nada cuando se trata de decidir sobre la moralidad de la clonación humana.

En "Genetic Information and Moral Obligations" se cuestionan las obligaciones morales que aparentemente se desprenderían de nuestra habilidad tecnológica de obtener información acerca de nuestro material genético: la responsabilidad de conocer nuestra condición genética, la de informar a nuestros familiares de ella, y la de no tener hijos en los casos en los haya riesgo de transmisión de enfermedades genéticas o malformaciones.

De nuevo, de la habilidad técnica no se seguiría la responsabilidad moral. Afirmar lo contrario supone, entonces, volver a cometer los mismos y similares errores científico-técnicos y epistemológicos que ya hemos visto y que no están justificados si atendemos seriamente al conocimiento científico disponible. Éstos son: suponer 
que la información obtenida mediante las técnicas de testado genético es altamente predictiva; asumir, una vez más, el determinismo genético de la inevitablilidad de los desordenes y las enfermedades de origen genético; y presuponer también el reduccionismo de conceder a los genes el único papel relevante en el desarrollo de tales enfermedades, independientemente del contexto biológico y social. Es más, se estaría estableciendo otra vez la correlación entre la información genética obtenida y la valoración de las posibles consecuencias físicas de los mismos, obviando que conceptos como los de salud y enfermedad aplicados a los humanos son ellos mismos controvertidos.

En el capítulo siguiente, "Moral Obligations, Genetic Information and Social Context", se analiza cómo, aún tomando incuestionablemente el poder predictivo de tales técnicas e incluso obviando los errores hasta ahora señalados, las responsabilidades morales antes citadas no se justificarían, y esto porque estaríamos ante una mala interpretación moral: aquella que presupone obligaciones morales universales independientemente de su contexto de aplicación y surgimiento. Pues, aunque obtener información genética sobre nosotros mismos para ayudar a otros afectados y para evitar enfermedades hereditarias pueda parecer una obligación moral obvia, entender estas responsabilidades en maneras abstractas y descontextualizadas resulta poco útil para los seres humanos reales a los que esas obligaciones presumiblemente se aplican o, lo que es peor, podría resultar injusto.

Como con respecto al determinismo biológico mismo, los argumentos presentados en este libro por la autora no tratan de defender o rechazar estas tecnologías, sino de hacer ver la necesidad de no perder de vista el contexto en el que ellas aparecerán y en el que se están concibiendo. Respecto de esto último y para terminar, de Melo-Martín nos recuerda que los debates en torno a las biotecnologías no sólo encierran tal determinismo genético sino también la asunción de otras creencias tradicionales, por ejemplo las de corte positivista acerca del rol de la experticia científica en los asuntos públicos o sobre la neutralidad valorativa de la ciencia y la tecnología. A una parte significativamente amplia de los discursos académicos, políticos y del público en general sobre estos asuntos subyace aún el mito acerca de la ciencia, según el cual su potencial benefactor sólo depende de una mayor inversión y "mejor distribución de recursos como tiempo, dinero y energía intelectual” (p. 130), así como -debemos añadir nosotros- el determinismo tecnológico que nos hace creer que su aplicabilidad es inminente y sólo cuestionable en el contexto de su usabilidad.

De estos últimos apuntes, como del resto del libro aquí reseñado, se desprende claramente la formación de la autora en filosofía de la ciencia, de igual forma que su buen conocimiento de la perspectiva social de los estudios sobre ciencia y tecnología, aunque este bagaje intelectual apenas se refleje en la bibliografía utilizada. De la misma manera, los puntos de crítica filosófica más cercanos al enfoque de los estudios sobre ciencia, tecnología y sociedad (CTS), aun siendo destacados por ella, son los menos desarrollados, por lo que parece obvia su intención de presentar este trabajo en el marco bioético. 
Ciertamente, es la bioética el ámbito de competencia aparentemente más apropiado para debatir estos asuntos o, al menos, ésa es la situación más habitualmente. En España ha sido un comité de bioética el encargado de elaborar el informe experto base de la nueva propuesta de ley sobre investigación biomédica, tal y como la Ministra de Salud Elena Salgado ha repetido en tantas ocasiones. Lo que no es de extrañar si pensamos, no en su obvia relación con la práctica médica desde su origen, sino más bien en que en la actualidad, y de forma similar a como ocurre con la ecológica, la bioética se ha consagrado como la reflexión multidimensional y pluridisciplinar aparentemente más acertada para afrontar políticamente los dilemas derivados de los avances tecnocientíficos recientes, lo cuales se definen precisamente por esos mismos rasgos.

En efecto, son innumerables y de suma importancia los temas que se suscitan desde su perspectiva en torno a las biotecnologías. Si tomamos cualquier libro de bioética general o atendemos al contenido de sus circuitos académicos, encontramos la recurrente preocupación sobre cuestiones relacionadas con el uso y confidencialidad de la información genética de los individuos (tema en el que podemos incluir, también, desde la discusión acerca de los seguros médicos hasta la cuestión de las patentes), la experimentación con seres vivos (íntimamente relacionada con la cuestión acerca del estatuto ontológico de un embrión humano) o el omnipresente temor a las posibles derivas eugenésicas (tanto negativas como positivas). Ejemplos que se suman a los temas latentes en Taking Biology Seriously: sus consecuencias jurídicas (que incluiría el debate sobre el libre albedrío), políticomorales (que conciernen, además, a denuncias que van desde las posibles discriminaciones sociales en base a nuevas tipologías de ser humano, hasta los posibles cambios en las políticas públicas sanitarias, por ejemplo) y económicas (i.e., también en lo tocante a la posibilidad de acceso universal a técnicas que son muy complejas y caras).

A pesar de ser tantos los focos de su atención e, incluso, a pesar de que son todos ellos acertados y necesarios, la reflexión bioética se nos presenta deficiente, concretamente, en tanto que en general se reduce a ellos. Es decir, es la revisión crítica acerca de las últimas cuestiones citadas brevemente en el libro de Inmaculada de Melo-Martín, las mismas que coinciden con los temas que precisamente se ponen de relieve los estudios CTS, las que encontramos fundamentales. Desde tal perspectiva, la crítica a estas formas de debate no debería centrarse únicamente en qué toman o no en cuenta los dilemas bioéticos -en este caso el contexto social y/o el conocimiento científico-técnico disponible, como explicita Inmaculada de MeloMartín- pues son precisamente las relaciones entre las biotecnologías y la sociedad el centro de su atención, sino el cómo se hace. Pues, como también se puede desprender claramente del propio análisis de esta filósofa, es ahí donde residiría, por ejemplo, la dificultad de no poder tomar el contexto histórico-social como aquel en el que las nociones de enfermedad y salud se han construido. Precisamente, porque no se parte de una visión de la ciencia y la tecnología en la que se reconozca la posibilidad de cierto constructivismo o, simplemente, de un modelo que no admita por principio la distinción entre hechos y valores en la actividad tecnocientífica. En este contexto, y a pesar de que la bioética cuestiona el supuesto a priori del avance 
científico-tecnológico como bien público, y resaltando acertadamente con ello la pluralidad de dimensiones sociales (tanto beneficiosas como dañinas) de la implementación del conocimiento biotecnológico, parece mantener cerrada la caja negra correspondiente a la ciencia y la tecnologías mismas. Si este fuera el caso, el nuevo y celebrado rol de la bioética en el proceso deliberativo de toma de decisiones políticas no supondría más que una replica del sistema experto derivado del modelo lineal de desarrollo.

De la misma manera podría estar ocurriendo con el aparente debate público sobre estas cuestiones y el papel actual de la sociedad civil. A pesar de que gran parte de los resultados no deseados, por ejemplo de la incipiente terapia génica, se hacen públicos gracias a los medios de comunicación y otros mecanismos de la sociedad de la información, es precisamente esta aparente posibilidad de cuestionamiento social de las consecuencias de la investigación biomédica y su aplicabilidad lo que contribuye a una aceptación significativamente amplia del desarrollo biotecnológico por parte de la sociedad e, incluso, a que se siga manteniendo cierto optimismo respecto del progreso científico-tecnológico. ${ }^{1}$ Pero, como nos recuerda Sheila Jasanoff, ${ }^{2}$ estos debates públicos (en los que se incluye la reflexión bioética) definen la cuestión en marcos políticos, económicos, legales y científico-técnicos de la mano de expertos que, si bien nos hablan de derechos, riesgos, costes/beneficios, propiedad, dignidad humana, etc., no ponen de relieve, precisamente, que son las propias ciencias y tecnologías las que han estabilizado los términos en los cuales sus desarrollos actuales son descritos y debatidos.

Ante este panorama, en el que la reflexión bioética acerca de la clonación y las células madre se ha profesionalizado dentro del discurso institucional -no acerca de la naturaleza o propósito de las nuevas entidades a las que la biología está dando vida, sino más bien acerca el impacto en la seguridad y el orden social o respecto de las expectativas depositadas en ellas por parte de los ciudadanos- se vuelve necesario ampliar nuestro análisis acerca de las ciencias y las tecnologías a la propia naturaleza y alcance de las reflexiones bioéticas. ${ }^{3}$ Siendo también por esto que, en todo caso, la obra tomada aquí como referencia no sea un libro de bioética al uso en tanto que, precisamente, nos abre las puertas a tal cuestionamiento en el propio marco de su deliberación.

Inmaculada de Melo-Martín ha tomado, así, seriamente no sólo los conocimientos científicos disponibles y las dimensiones morales involucradas, sino las cuestiones epistemológicas y supuestos científico-técnicos de fondo, convirtiendo Taking Biology Seriously en un trabajo que enriquece profundamente el debate bioético, el cual, como ya se ha señalado, raramente cuestiona la neutralidad valorativa de la ciencia y la tecnología mismas, centrándose en la reflexión moral, política, jurídica y/o económica acerca de las consecuencias de su aplicabilidad.

\footnotetext{
${ }^{1}$ Emilio Muñoz (2001): Biotecnología y sociedad: encuentros y desencuentros, Cambridge University Press OEI, Madrid, p. 157.

${ }^{2}$ Sheila Jasanoff (2005): Designs on Nature. Princenton University Press, Princenton, pp. 171-172.

${ }^{3}$ Ibíd., p. 201.
} 